\title{
La apropiación audiovisual y la autoproducción. Entre una práctica artística y una táctica cultural
}

\section{Audiovisual appropiation and self-production. Between artistic practice and critic tactic}

\author{
Sagrario Martín Rodríguez
}

Investigadora (Universidad Complutense de Madrid)

Fecha de recepción: 29 de abril de 2014

Fecha de revisión: 31 de julio de 2014

Para citar este artículo: Martín Rodríguez, S. (2014): La apropiación audiovisual y la autoproducción. Entre una práctica artística y una táctica cultural, Icono 14, volumen (12), pp. 362-394. doi: 10.7195/ri14.v12i2.719 


\section{Resumen}

La apropiación audiovisual es analizada en esta investigación como fenómeno ante la omnipresencia de los medios, la ubicuidad de la imagen, el progreso tecnológico, etc., que han transformado nuestros hábitos visuales y también cómo han afectado al mundo del arte.

Se van a analizar cómo los paradigmas tradicionales han sido modificados en cuanto a la forma de concebir la creación artística y la manera de enfrentarse a las imágenes audiovisuales del creciente paisaje mediático.

Por último se realizará un breve apunte de la apropiación audiovisual como respuesta posmoderna a los nuevos espacios y políticas de los medios dominantes de producción, subvertir los roles tradicionales en la creación y desmantelar los significados impuestos.

\section{Palabras clave}

Apropiacionismo - Posmodernidad - Táctica cultural - Autoproducción - Arte

\section{Abstract}

The audiovisual appropriation is analyzed, in this investigation, like a phenomenon facing the media omnipresence, image ubiquity, technological progress, etc., that has transformed our visual habits and also affected art's world.

We are going to analyze how the traditional paradigm has been modified regarding the artistic creation perception, aswell as, the way of facing audiovisual images in the growing media landscape.

Finally, we will make a brief note about the audiovisual appropriation as a postmodern response to the new dominating production media spaces and politics, that undermines the traditional creation roles and dismantles the impose meanings.

\section{Key Words}

Appropiacionism - Posmodernity - Cultural tactic - Self-production - Art 


\section{Introducción}

La naturaleza cada vez más medial de las sociedades provoca que sea necesaria una profundización sobre el horizonte y papel del arte en la creación cultural. Para lo cual se necesita reflexionar sobre viejas creencias y fijar su carácter pragmático acorde a una sociedad cada vez más tecnificada y global.

Por otra parte, los medios electrónicos y los nuevos dispositivos están configurando el modo en el que el ciudadano se sitúa y afronta cuestiones apremiantes de la sociedad y la cultura. Tal como apunta Canclini (1995):

Las formas argumentativas y críticas de participación ceden su lugar al goce de espectáculos en los medios electrónicos, en los cuales la narración o simple acumulación de anécdotas prevalece sobre el razonamiento de los problemas, y la exhibición fugaz de los acontecimientos sobre su tratamiento estructural y prolongado. (p. 25).

La producción artística posmoderna precisamente es una crítica de cómo se recibe el arte en la cultura, los procesos sociales derivados, y la falta de profundidad crítica. Así mismo, las fronteras que distinguen entre el arte y "no arte" cada vez están más difuminadas.

El apropiacionismo como reubicación de ciertos productos artísticos y de productos de los medios de comunicación, reafirma esta problemática. Esta práctica ha penetrado en otros ámbitos no artísticos y juega a romper, descomponer y al mismo tiempo recomponer piezas y unidades de discurso en una nueva visión coherente. Ante el vasto paisaje de productos audiovisuales y su consumo, la práctica apropiacionista se convierte, más que en una moda o tendencia, en una consecuencia natural.

Las barreras materiales de acceso, reproducción y distribución de información y material audiovisual han caído. Las herramientas informáticas y dispositivos digitales son cada vez más versátiles, por tanto, más accesibles para los usuarios, y por tanto, posibilitan la autoproducción. 
En este artículo se va a situar la apropiación audiovisual como práctica ciudadana en general, y principio creativo en particular. Para ello se abordarán las cuestiones más controvertidas dentro del arte contemporáneo -que no sólo afectan al mundo del arte-, como es la "estetización" o la falta de compromiso social del arte; la crítica institucional y la posibilidad de nuevos espacios para el arte; así como cuestiones como la autoría y la recepción y consumo cultural. Además, se hará un apunte de los límites legales subyacentes en esta práctica, por lo que se verá el copyright como limitación legal a la vez que creativa.

Se va a prestar especial atención a aquellas obras más próximas al ámbito artístico que supongan una crítica de los signos representacionales $\mathrm{y}$, por tanto, de las relaciones de poder. Además de aquellas más próximas a la espontaneidad ciudadana en los usos y aquellas que constituyen un intento de conectar la cultura con la praxis cotidiana.

\section{Objetivos}

- Analizar la práctica apropiacionista en el marco de la estetización, la crítica institucional y la relación productor/artista y espectador /consumidor, para determinar su impacto sobre la esfera de la experiencia estética y la producción artística.

- Ubicar a la apropiación audiovisual dentro de los fundamentos que sustentan la teoría posmoderna, en la que además el espectador/oyente se involucra en el proceso de comprender, interpretar y crear diferentes significados.

- Describir los nuevos espacios de creación contemporánea en Internet. En especial, aquellos relacionados con la práctica de la apropiación audiovisual para definir cuáles son sus características y posibilidades.

- Establecer puntos de contacto que sitúen el apropiacionismo como fenómeno artístico y como táctica ciudadana y crítica. 


\section{Material y métodos}

Debido a la intención de los objetivos de inscribir la apropiación audiovisual dentro de los estudios sobre el arte contemporáneo y aquellos ligados a la cultura mediática, se ha procedido a una consulta bibliográfica de cierta notoriedad sobre estos temas para establecer los puntos cardinales sobre la contextualización teórica de esta práctica, establecidos en los distintos apartados.

Se ha intentado seleccionar como base los textos que sirvieron como punto de partida para ulteriores investigaciones sobre estos puntos y sus consecuencias, para descender en investigaciones más actuales y más específicas sobre el tema del apropiacionismo y los nuevos espacios de creación y comunicación.

Tras una revisión y análisis cualitativo de estas cuestiones centrales, se han podido inferir dos grandes tipologías de esta práctica en la Red, el medio donde convive como práctica artística y como táctica cultural:

- Crítica de los modos de representación y relaciones de construcción de significado de las imágenes.

- Definición de nuevos espacios de creación y colaboración. Cultura intersticial.

Los ejemplos utilizados se cogerán básicamente de youtube, vimeo o blogs, y serán escogidos de acuerdo a su adecuación a estas tipologías y las pretensiones que se intuyen en su autor o autores.

Para concluir se han formulado algunas anotaciones sobre los resultados obtenidos, y sobre las posibilidades de esta práctica bajo los puntos estudiados.

\section{Aproximación al concepto de apropiación audiovisual}

Las categorías tradicionales para designar la cultura contemporánea de la imagen en movimiento resultan imprecisas y necesitan ser matizadas. Cine o videoarte son conceptos que dejan indefinida una buena parte de la producción audiovisual. 
Pues ambos tienden a fundirse en la órbita de los formatos digitales. Su estudio tiene especial relevancia en la heterogeneidad de las prácticas audiovisuales alternativas.

Es difícil calificar en ocasiones estas prácticas, ya que depende de la finalidad, el contexto de su recepción, las formulaciones teóricas y estéticas, y la procedencia del material que la compone. No obstante, se puede comentar que la apropiación audiovisual hunde sus raíces en diversas prácticas del videoarte y cine experimental, o en la actividad de los situacionistas o détournement (Paris, s.f; Bourriaud, 2009; Vilches, 2009).

Es complicado establecer tipologías en esta práctica audiovisual dependiendo del grado de apropiación, tanto de la imagen como del sonido. Pueden ir desde la apropiación ínfima, sólo cambiando el contexto de exhibición; desde la intervención sobre la imagen, en muchos casos hasta hacerla irreconocible; o también, con la combinación de diversas fuentes de distinta procedencia, tanto sonoras como visuales. El espacio de exhibición también es importante, no sólo se presenta en modo monocanal, sino que aparece en diversas formas como las videoinstalaciones o el net.art, ligadas al ámbito artístico y a soportes y recursos informáticos (Vilches, 2009).

Internet, es el medio en la actualidad donde se establecen más relaciones de apropiación audiovisual, en cuanto a medio de distribución de obras apropiadas y apropiacionistas. Prácticas como por ejemplo los mash-up: creación a partir de varias fuentes; o re-cut: parecido al tráiler cinematográfico. Ante el éxito popular que tienen algunas de estas producciones, se convierten de hecho, en videos virales que las grandes corporaciones e industrias los integran para utilizarlos como publicidad para sus películas, vídeos o spots (Vilches, 2009, p.45).

Algunos de los términos más relevantes que contemplan este nuevo panorama cultural y medial del audiovisual son:

- “Desmontaje", analizado por E. Bonet (2002), un término alternativo al found footage o "metraje encontrado", que recuerda al objet trouvé dadaísta, y que por la referencia del término al cine, se hace necesaria una rede- 
finición de acuerdo con la producción audiovisual actual (Vilches, 2009). El desmontaje surge de una confrontación antagónica con el montaje, por lo que a través de la apropiación audiovisual se destruiría el sentido lineal y constructivo propio de éste, y se alterarían sus características fundamentales.

Este autor sitúa esta práctica en la evolución de la cultura de archivo, formado en las herencias del cine documental o de "montaje". Un discurso es construido a través de imágenes de reportajes o crónicas, y entre lo que él denomina "deconstrucción alegórica" de las imágenes provenientes de los detritos audiovisuales (Bonet, 2002), ya que los nuevos dispositivos y espacios multimedia han facilitado la posibilidad de acopio, disponibilidad y en cierta manera, visibilidad pública.

Si el documental se distingue por la objetividad y la neutralidad, esta práctica quedaría enunciada bajo criterios de subjetividad y actitud crítica con respecto a los modos de representación (Bonet, 2002).

- "Postproducción", lo introduce Bourriaud (2009). Hace referencia de forma obvia a la manipulación que se realiza normalmente después de la filmación en la producción audiovisual, pero en este caso con la salvedad de que las imágenes ya están producidas. Lo que indica este autor es que la obra de arte apropiacionista está inscrita en una red de signos y significantes. Lo que se trata es de:

Inventar protocolos de uso para los modos de representación y las estructuras formales existentes. Se trata de apoderarse de todos los códigos de la cultura, de todas las formalizaciones de la vida cotidiana, de todas las obras del patrimonio mundial, y hacerlos funcionar (Borriaund, 2009, p. 14).

Lo interesante de su reflexión es que el autor reclama una "reprogamación" de las imágenes para poderlas subvertir, interrogar e incluso "habitar" (Bourriaud, 2009).

DOI: ri14.v12i2.719 | ISSN: 1697-8293 | Año 2014 Volumen 12 № 2 | ICONO14 


\section{La apropiación como actividad artística. Condi- cionantes y problemáticas}

Uno de los pensadores más influyentes en la teoría del arte del siglo pasado, relacionado con la irrupción de los dispositivos tecnológicos en la creación artística es Walter Benjamin. Este autor enunció una nueva fenomenología de la situación inédita que supondría la inclusión de las tecnologías "reproductoras", apelando a la condición material de la obra y estableciendo una oposición en relación a la genialidad, la originalidad y el misterio (De la Cuadra, 2007, p. 4). Que asimismo, supondría una reflexión sobre la dependencia del contexto institucional del arte y del discurso histórico por él determinado (Martín Prada, 2001, p. 13). Una dependencia que ostentaba férreas relaciones de poder, promulgada en muchos casos por la representación artística.

El discurso posmoderno es el que mejor sienta las bases de por qué se han ido eliminado agentes tradicionales en la creación artística, tal como propusiera Benjamin, y en relación a la neutralización y naturalización de ciertas prácticas que promovían una crítica contra la institucionalización del arte.

La reflexión de los "modos de significación" establecida por Benjamin, dan buena cuenta de la experiencia perceptual de las colectividades que en este momento están dominadas por la tecnología y la industrialización La experiencia sensorial, sin duda, se modifica profundamente según Benjamin, gracias a la reproductibilidad inherente a las tecnologías de la imagen, que "transforman la posibilidad de la memoria y archivo" (De la Cuadra, 2007, p. 8).

Inundados de propuestas artísticas y por las visualizaciones de la imagen técnica, lo extensivo del arte progresa casi ilimitadamente y rebasa a lo intensivo (Marchán Fiz, 2005, p.89), sobre todo, con la conquista de la ubicuidad ${ }^{1}$ de la imagen favorecida por la aparición de lo digital. Los objetos cotidianos o imágenes mass mediáticas compiten con la obra artística en nuestra mediación con lo real (Marchán Fiz, 2005, 89), como consecuencia, surge una génesis independiente de realidad. Para De la Cuadra (2007) es precisamente esta suerte de "hiperreproductibilidad digital" la que conforma nuestro régimen de significación, y también la retórica de la imagen fotográfica como punto de vista impuesto (Paris, s.f).

ICONO14 | Año 2014 Volumen 12 N² 2 | ISSN: 1697-8293 | DOI: ri14.v12i2.719 
La apropiación por tanto, surge de forma coherente en un entorno cada vez más mediatizado. La disponibilidad de la imagen digital, la aparición de un continuum sensorial dominado por los productos de los medios tecnológicos audiovisuales, enfrenta al espectador/artista a una reelaboración necesaria.

\subsection{La estetización: "Una fruición sin reflexión"}

Benjamin (1990) hizo notar el modo en que el público se relacionaba con el arte. Sus estudios sobre los medios de reproducción técnica eliminaban el carácter aurático de la obra de arte y la desmitificaban. Esta consecuente desacralización imponía un nuevo estatus a las obras y por tanto una disociación crítica entre la masa y el arte, privilegiando una actitud fruitiva y superficial.

Puede resultar contradictorio que debido a este fenómeno advertido por Benjamin, las imágenes artísticas se convierten en visuales, situación que se disimula en cierta manera, al convertirse las imágenes visuales en estéticas por el omnipresente fenómeno de la estetización (Marchán Fiz, 2005):

La estetización de las imágenes visuales en su variedad está imponiéndose como el correlato de una progresiva desartización ${ }^{2}$ o minoración del arte en las prácticas que se apropian y reelaboran las imágenes y los objetos encontrados (p. 89).

En la posmodernidad se podría enunciar que existe una suerte de tendencia "positiva"3 en favor del aspecto estético de la obra (Martín Prada, 2001, p. 20). Emergen cuestiones que hacen enmarcan la acción del arte en la categoría de lo sublime. En relación a esta cuestión, De Bal (2003) advierte el error conceptual por parte de la teoría estética en la definición de la experiencia de lo sublime, como lo "inefable" ligado al concepto de arte elevado. La autora comenta que es necesario un compromiso con la historicidad del término para entender la aplicación de lo sublime. Un término que sirve a diversos propósitos, entre los cuales está el manifestar la resistencia de los objetos visuales al lenguaje, bajo la máxima "una imagen vale más que mil palabras" (De Bal, 2003, p. 9).

DOI: ri14.v12i2.719 | ISSN: 1697-8293 | Año 2014 Volumen 12 №2 | ICONO14 
De alguna manera esta tendencia se muestra como una disolución del pensamiento crítico a favor de disfrutar de la parte más superficial de la obra.

Basada en una cierta apelación de las imágenes contemporáneas por distintos medios a la subjetividad, se produce "una sensibilidad hiperestimulada" (Martín Prada, 2001, p. 19). Jameson (1991) comenta que si el arte cohesiona a través de aspectos emocionales y sensitivos, en una crítica a esta tendencia, que sólo se centra en los aspectos epidérmicos de la obra, también se enunciarán las contradicciones sociales que determinan ciertas instancias de poder.

La imagen cinematográfica, situó al espectador en una condición nueva en relación al flujo espacio-temporal y exigía a éste una adaptación de los mismos a su experiencia sensorial, hecho que se vio mucho más ratificado con la aparición de la televisión y su inclusión del "directo" como conexión inmediata con la realidad. De la Cuadra (2007, pp. 14-15) relaciona esto con el "shock" como un principio formal basado en lo fragmentario de la recepción de la imagen, lo fugitivo y múltiple a través de los diferentes dispositivos, medios y formas en las que nos llegan las imágenes.

En relación a esta disolución de una permanencia del tiempo, de lo sensitivo, o de una idea, vemos que en la imagen audiovisual, cuando se intenta elaborar a través de la misma una información, establecer relaciones o reflexionar, ésta ya se ha modificado, y es ese mismo fluir, el que impide cualquier tipo de consideración fuera de lo superficial de estas imágenes (Benjamin, 1990, p. 51).

Cindy Sherman, se apropia de encuadres del cine clásico americano, para la elaboración de sus fotografías Untitled Film Stills (1977), imitando sus poses, vestimenta, etc. Elabora una crítica contra los estereotipos femeninos del cine (Colorado Nates, 2012). Estas imágenes apelan al espectador cinematográfico, y lo sitúan en una posición de extrañamiento, ya que las imágenes resultan familiares, pero a la vez son desconcertantes debido a la nueva contextualización (Martín Prada, 2001 pp. 64-66).

Hay que hacer notar que la crítica representacional que hace la artista se produce de un modo curioso, al utilizar imágenes "congeladas" para apelar a un medio

ICONO14 | Año 2014 Volumen 12 N² 2 | ISSN: 1697-8293 | DOI: ri14.v12i2.719 
cuyo fundamento es la imagen en movimiento, como es el caso del cine. En relación a lo que se ha comentado, la artista nos devuelve ese estado contemplativo y no volátil propio de las imágenes fijas que enfrenta a quien las mira a la propia resistencia ante los nuevos flujos temporales.

Bück-Morss (1992), realiza un análisis a raíz de las aportaciones de Benjamin, en el que se considera una redefinición sobre la estética. Para ello, en primer lugar, pone el acento en el sentido etimológico del término como el acto de percibir a través de los sentidos (Búck-Morss, 1992, p. 6), más que la asociación tradicional ligada exclusivamente a los productos artísticos. La autora denuncia una crisis perceptiva producida en parte por la sobreestimulación donde la ausencia de respuesta se convierte en algo razonable y necesario para "sobrevivir", donde:

Bombarded with fragmentary impressions they [the eyes] see too much and register nothing. Thus the simultaneity of overstimulation and numbness is characteristic of the new synaesthetic organization as anaesthetics. The dialectical reversal, whereby aesthetics changes from a cognitive mode of being "in touch" with reality a way of blocking out reality, destroys the human organism's power to respond politically ${ }^{4}$ (p. 18).

Lo repetitivo y redundante se convierte para Bück- Morss en "anestésico" más que en estético (como forma de cognición), donde el arte y los productos visuales de los medios tecnológicos se convierten en una realidad compensada ante la saturación de estímulos que se reciben, y que ella denomina "fantasmagoría" (BückMorss, 2005, p. 22). Una posible activación consciente a través de los sentidos pudiera ser un "sistema sinestésico" que ofrezca mecanismos a través del cuales se potenciara la memoria en el encuentro de las imágenes externas con las internas, ya que "Without the depth of memory, experience is impoverished"5" (Bück-Morss, 1992, p. 16).

Según Martin Prada (2005, p. 131), las imágenes ya no constituyen un medio, resultado de reflexiones filosóficas y lenguaje que sostienen diversos fines. La imagen constituye pensamiento. Y por tanto, la representación -posible a través de la imagen-, se torna independiente del conocimiento y del significado. 
Además, a diferencia de lo analógico, lo digital no implica un proceso de reproducción de la realidad, sino que la produce, se emancipa de su referente (De la Cuadra, 2007, p. 18).

Si la forma de la experiencia queda estetizada por completo, queda por plantearse qué función corresponde a lo artístico, a no ser que se suponga que el arte garantiza el "entregarnos a la desorientación profunda de un mundo sin verdad" (Brea, 2002, p. 151).

\subsection{Crítica a la institución artística. Legitimación y apertura de nuevos espacios para el arte}

Después de las vanguardias históricas, se inician varias prácticas que tienden a desmaterializar el objeto artístico para ligarlo a terrenos de la experiencia inmediata. A esta cuestión se le puede añadir que tal como hace notar Verdú Schumann (2004), la legitimidad de una obra, después de la ruptura duchampiana, relega al contexto expositivo la capacidad de albergar la artisticidad de un producto. En este punto resulta interesante citar a la apropiación de la obra de Duchamp "L.H.0.0.Q" (1919) o ready-made rectificado (Jiménez, 2004, p. 27) de "La Mona Lisa", donde realiza una "intervención" llevando al extremo la noción de ready-made, pero esta vez no utiliza ningún objeto industrial, sino que utiliza una reproducción de una obra para hacerla de nuevo arte, situando a quien contempla en una situación dialéctica de acuerdo a la relación visual del espectador con la obra de arte tradicional (Martín Prada, 2001, p. 75) y además, se producen diversas respuestas que oscilan entre las que ven en la intervención del artista una obra de arte y una simple intervención sobre una reproducción y por tanto, "no arte". De esta manera Duchamp provoca la tensión incipiente de la pérdida aurática y cultual como consecuencia de los medios de reproducción y la legitimidad del espacio expositivo y la decisión y selección del artista. Duchamp en este sentido revoluciona las bases del proceso creativo, no ligado ni a la producción ni a la realización, en el sentido tradicional del término. Socava el carácter físico y material, lo que los antiguos griegos llamaban poiésis y la tradición desde el Renacimiento lo denominaba "creación" (Jiménez, 2004, p. 29).

ICONO14 | Año 2014 Volumen 12 Nº | ISSN: 1697-8293 | DOI: ri14.v12i2.719 
Warhol, paradigma de nihilismo en el arte contemporáneo, también se apropia de la obra de Leonardo; por ejemplo, en su versión "Treinta mejor que una" (Figura 1) se puede comprobar que más que un desplazamiento sobre el conocimiento histórico vigente, celebra lo icónico de la obra de arte a la que hace referencia. Warhol invita al consumo a través de la repetición, a través de elaborar un discurso fetichista sobre la mercancía, en este caso la obra de Leonardo es mercantilizada y transformada en múltiples imágenes y por tanto, remarca aún más la independencia de la obra original apropiándose de su superficie (Jameson, 1991, pp. 28-30).

Estas obras apropiacionistas son un buen ejemplo de lo que sucede en la actividad contemporánea. La efectividad de ambas obras no se produce a juicio de Martín Prada (2001) por igual, pues en la de Warhol no pierde ese carácter mítico propio del arte tradicional; de hecho, si observamos las obras desde la afirmación del "todo vale"- dudosa afirmación pluralista-, conduce a la reflexión que un tipo de arte es más efectivo en cuanto que ofrece una crítica de la representación que al que se limita a hacer un mero ejercicio de ésta (Brea, 2002, p. 159).

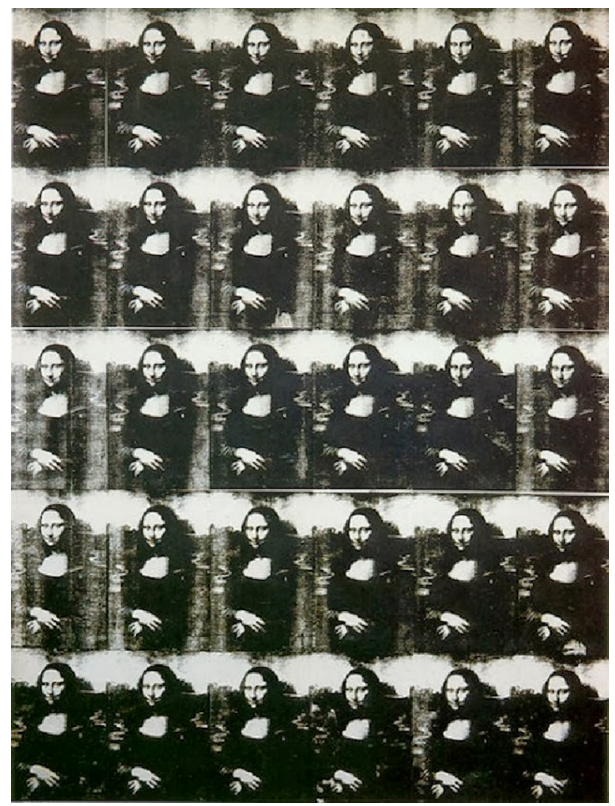

Figura 1: Treinta son mejor que una (Thirty are better than one (1963). Col. Particular. Andy Warhol. Recuperada de http://giocondaintervenida.blogspot.com.es/2013_10_01_archive.html 
En un sentido muy próximo al que proponía Duchamp, parte de la crítica posmoderna procede a desarticular el discurso histórico del tópico de "verdad del arte".

También parte de la misma trata de evidenciar a quiénes estaría beneficiando esos presupuestos de verdad creada en las distintas representaciones. No interesaría tanto el contenido de la imagen, lo narrado, sino cómo esa narración está unida a cuestiones ideológicas e históricas. Por esto, la intención del apropiacionismo no es cambiar la "conciencia" de lo que es valioso y legítimo a nivel cultural, sino precisamente el propio régimen institucional de lo que es la producción de esta supuesta valía (Martin Prada, 2001 pp. 25-29).

Además, en vez de posar la atención hacia objetos más conocidos y dentro del paradigma de las obras artísticas tradicionales, y reducir el ámbito de la contemplación e imaginación en la fruición con las obras tradicionales, lo que Mitchell (2005) propone es abrir el abanico estético a productos visuales de grandes industrias del cine, de vídeo, de la televisión, e incluso las nuevas aportaciones de la Red. Esta apertura se debe en parte a la expansión tecnológica que ha propiciado una nueva experiencia estética, donde en el arte, tal como se observa en la obra comentada de Warhol, se produce una ósmosis con el diseño, la publicidad y los mass media (Jiménez, 2004, p. 34). Hay que tener en cuenta que una nueva forma artística surge necesariamente a raíz de un desarrollo técnico, sobre todo cuando éste produce transformaciones profundas en la relación del individuo con su propia existencia y con la comunidad. Por esto, estos cambios, necesitan nuevos soportes y narrativas (Brea, 2002, pp. 163-165).

La problemática que subyace en la voluntad de ampliar el "proyecto estético", radica en la recepción cultural de las obras, pues si el carácter legimitador reside en el público (Verdú Schumann, 2004), para éste resulta todavía difícil desvincularse de la institución para la apreciación artística debido a que su hegemonía está avalada por diferentes mecanismos como por ejemplo, el educativo y político. Más aún cuando la creación artística se mueve según las reglas de las innovaciones y la obsolescencia periódica. "Las manifestaciones culturales han sido sometidas a los valores que 'dinamizan' el mercado y la moda: consumo incesantemente renovado, sorpresa y entretenimiento" (Canclini, 1995, p. 17).

ICONO14 | Año 2014 Volumen 12 N² 2 | ISSN: 1697-8293 | DOI: ri14.v12i2.719 
Por otra parte, las manifestaciones artísticas que abanderan un movimiento anti-institucional y crítico, se encuentran también en la difícil posición de difundir su mensaje.

Al hilo de esta cuestión, hay que comentar que, al igual que las obras que intentaron crear rupturas con la labor museística e institucional, como por ejemplo en el Land Art, fueron absorbidas por el museo. Lo mismo sucede con el videoarte, que buscaba a toda costa hacerse independiente de los recursos lingüísticos del cine o de la televisión. Si se hace una revisión sobre sus orígenes, se puede comprobar que uno de los condicionantes que resultó fructífero para su implantación como medio de expresión consistió en las enconadas críticas al creciente control informativo. Los artistas veían en este medio una posibilidad subversiva contra el carácter unidireccional de los productos mediáticos audiovisuales, sobre todo el televisivo. Pero tras un fracaso de inscribirse en los hábitos visuales generados por la televisión, los videoartistas realizaron un acercamiento a la institución del museo para crear un clima de acogida dentro del público, que ya poseía una predisposición adquirida a encontrarse con arte dentro del museo (Verdú Schumann, 2004). Obviamente, esta cuestión choca al pensar la difícil conciliación que posee el arte contemporáneo con el público, hasta derivar incluso en el rechazo.

Hay que apuntar que las formas de arte electrónico convergen en la Red. La importancia del net.art se fundamenta en usar la especificidad del medio para explotar al máximo la interacción y comunicación con el usuario para crear contenidos a partir de sonidos, texto e imagen (Baigorri y Cilleruelo, 2006, p.11). Al mismo tiempo la Red supone un soporte mediático de difusión de las obras que a veces no corresponde con net.art y su contenido no guarda relación con Internet. Uno de los problemas a los que se enfrenta este tipo de obras es la difícil focalización o captación de atención por parte de los usuarios ante la inasible información que la misma contiene. Sobre todo en un "medio en el que prima la velocidad sobre la reflexión y la cantidad sobre la calidad" (Verdú Schumann, 2004, p. 1029). El carácter "rizomático" de la Red aniquila cualquier pretensión de encontrar saber 0 información, pues se disemina y despliega de forma imparable. Cualquier contenido o conocimiento "ha de ser leído a través de otro" (Brea, 2002, p. 183). 
En la Red, también se pueden comprobar ciertas injerencias que hacen que se pierda esa característica horizontal del medio, y al establecer ciertos sesgos que jerarquizan la información y que facilitan una serie de conductas prefijadas generadoras de una "moda" o mainstream.

Ante la aparición de esquemas de control en la Red, surgen y se desarrollan movimientos activistas y de resistencia, que van de la acción directa para sabotear la navegación y la estructura de webs, hasta las más "radicales" o hacktivistas, que reivindican derechos como la posibilidad de un código abierto, derecho a la privacidad y la encriptación, o la independencia en el uso de servidores (Brea, 2002, p. 80), o en el terreno artístico -artivistas-, que luchan contra la emulación de las convenciones artísticas en Internet, como es el caso de los derechos de autor, objetualización, comercialización, etc. (Baigorri y Cilleruelo, 2006, p. 168).

Internet se convierte por tanto en un medio donde se han depositado fuerzas renovadoras y esperanzas democratizadoras en la creación y experiencia artística, pero de efectividad no completa y discutible, ya que las estrategias y políticas de control se están afianzando (Smiers, 2006).

\subsection{La apropiación y la nueva reconfiguración de autoría y consumo}

\subsubsection{Medios de producción y reproducción. La aparición de un nuevo "autor"}

Si pensamos en la apropiación audiovisual como una construcción de un discurso audiovisual a través del ensamblaje o intervención sobre la obra de otros, y que además esta práctica pueda tener validez artística, es lógico pensar que se planteen cuestiones convencionales como la autoría.

Las indefinidas fronteras entre la producción cultural y el consumo hacen emerger además una reflexión sobre la reorientación de la aplicación práctica de la actividad artística, y además que

La acción y desmantelamiento de los códigos de comunicación existentes mediante la recombinación de algunos de sus elementos en estruc- 
turas que puedan ser usadas para generar nuevas imágenes del mundo (Martín Prada, 2005, p. 136).

En este sentido se produce una dislocación del discurso, una fragmentación, que hace que quede olvidada una forma unívoca de ver el mundo y los discursos que sustentaban esta idea.

La "muerte del autor "de la que habla Barthes (2009), es una alusión a la construcción moderna del autor, y pone en duda su existencia puesto que quien "habla" es el texto. Éste es posible a través de múltiples escrituras sin ser ninguna la original y el texto se compone de un tejido de citas y referencias provenientes de distintos focos de la cultura ( Barthes, 2009, p. 80).

El apropiacionismo refleja, en cierta manera, la propuesta de Barthes, en la que la verdad está "en la escritura", y que además la verdadera unidad del texto no está en el mismo, sino que está en la respuesta ocasionada por el espectador/lector. Por lo que este tipo de práctica artística, utiliza la obra como referente para desarrollar su potencial en su exterioridad, en su destino (Martín Prada, 2001, p. 73).

La desaparición del autor implica la aparición del lector, que es quien determina en cada caso el significado de un texto u obra y produce multiplicidad de variables significativas. Foucault (1984, citado en Irvin, 2005, p. 123) está de acuerdo con esta idea y va más allá, al indicar que la figura del autor supone un modo tiránico al coartar la libertad de pensamiento en el lector.

Aunque la práctica apropiacionista no es nueva, Irvin (2005) indica que no por casualidad surge una tendencia a partir de los 60 del siglo pasado que converge con las reflexiones de Barthes y Foucault, que cuestiona y choca con la idea tradicional del artista. Según Irvin (2005), los artistas apropiacionistas parecen eludir cualquier responsabilidad sobre el significado, ya que sólo se apropian de las "voces" de otros y las hacen propias. Esta autora sin embargo, defiende en estos trabajos una clara relación de autoría con las obras incautadas por los artistas, analizando cuestiones como la innovación, la intencionalidad artística, y la responsabilidad artística sobre su obra. A pesar de la "muerte del autor" anunciada por Barthes, su función sigue perdurando (Martín Prada, 2001, p. 70). 
Por lo tanto, no son importantes ni los medios de producción, ni el objeto final (Irvin, 2005, pp. 129-133).

Serrie Levine, una de las artistas apropiacionistas más conocidas, propone "re-fotografías" en su serie de After Evans, o sus versiones de obras de Duchamp o de Matisse, donde enfrenta al espectador a una situación de desorientación y de desconcierto ante la falta de originalidad, y de mérito creativo (Martín Prada, 2001; Irvin, 2005), además de romper con la tradicional idea convencional -casi teológica- de creación a partir de la nada. Por lo que enfrenta al público a una situación nueva, donde éste tiene que reflexionar e intuir cual es el juego propuesto por el autor en la identificación de creación de significados (Irvin, 2005).

Según Barthes, los surrealistas desacralizaron la figura del autor con su "escritura automática" o con los "cadáveres exquisitos", donde proponen una obra de producción colectiva, al mismo tiempo que se evidencia la imposibilidad de destruir un código, sino simplemente de burlarlo (Barthes, 2009, p. 78).

En esta línea, la llegada de Internet favorece y posibilita la implantación de "comunidades de productores de medios", o sea, una red de trabajo colaborativo y de autoría múltiple, que en realidad se trata de prácticas neoformales que crean espacios de trabajo a través de la práctica artística en la Red, y buscan una comunicación directa con los ciudadanos alejada de los intereses de las grandes corporaciones y los aparatos del estado (Brea, 2002, p. 48).

Alberich y Roig (2009) analizan también la autoría en los sistemas multimedia bajo el carácter revolucionario del medio en la creación de obras colectivas y colaborativas. El hipertexto, por ejemplo, favorece la construcción compartida de obras llevadas a cabo por diversos usuarios, por lo que la figura del autor en este medio se encuentra con la del lector. La posibilidad de la interacción deja atrás una actitud pasiva y lineal para dar paso a un usuario "coautor", y participa así, en una autoría derivada (Alberich y Roig, 2009, pp. 88-89).

ICONO14 | Año 2014 Volumen 12 Nº | ISSN: 1697-8293 | DOI: ri14.v12i2.719 


\subsubsection{Recepción cultural activa. Un modelo de usuario}

Certeau (2000) advierte que los usuarios de los productos culturales se muestran como una audiencia activa, puesto que en sus "modos de hacer" desarrollan tácticas de negociación en sus usos mediático-culturales de lo cotidiano. La táctica, según este autor, se define como "la acción calculada que determina la ausencia de un lugar propio [...] Debe actuar en el terreno que le impone y organiza la ley de una fuerza extraña" (Certeau, 2000, p. 43). El consumo para este autor consiste en el acto de apropiarse, utilizar o practicar los productos culturales, pero a través del desarrollo de "tácticas" como punto de resistencia. Servirse de un objeto, en este caso, es interpretarlo a la vez que puede ser modificado (Bourriaud, 2009).

Al hilo de esta cuestión, Bück- Morss (2005) conviene que en el acto de copiar y pegar una imagen de Internet, surge la apropiación de la misma, no como algo cuya autoría pertenece a otra persona, sino como sustancia de la propia experiencia visual de cada uno (p. 157). Esta imagen es susceptible de ser manipulada, pero a juicio de la autora se obtiene una nueva imagen, una nueva percepción, y cuando ésta última se ha fijado, su significado se activa y se pone en marcha (Bück-Morss, 2005, p. 158).

El consumo por tanto, puede ser considerado como un acto creativo y clave en la definición de la identidad cultural y de ciudadanía. Pues más que en valores abstractos de democracia, existe una tendencia a identificarse en las actuaciones que acontecen en la esfera del consumo privado. Si al consumir se elige, se define el ser y sentido social, convendría reflexionar si la apropiación de signos y bienes se pueden convertir en formas más activas de participación, y sobre el papel de los medios, donde se forman los gustos masivos y la ciudadanía (Canclini, 1995, pp. 27-30). En la actualidad el medio por excelencia es Internet.

Hay quienes apuestan por una propuesta activa y activista en la Red. Siguiendo una idea de Demers y Vorn (1995, citado en Baigorri y Cilleruelo, 2006, p. 21), existen dos tipos de actitudes ofrecidas al usuario-actor. La primera es una actitud implantada (Implanted behavior), fácil de predecir, pues se programan respuestas prefijadas, a través del sistema de acuerdo a reglas simples. Y la segunda, obedecería a una conducta emergente (emergent behavior), que se configura a raíz de 
la suma de todas las respuestas individuales ante una situación novedosa y no tan fácil de predecir, ya que dependen de un número cada vez mayor de posibilidades. De esta manera quedarían definidas respectivamente bajo los calificativos de "rutinaria" y "creativa". Para Baigorri y Cilleruelo (2006) estos dos tipos de conductas muestran dos tipos de actitudes también de los usuarios en Internet: una obedecería a la simple navegación "no lineal" o a través del hipertexto, y la otra a una serie de estrategias que favorecen la aportación del usuario y su participación en las obras de arte. La novedad del arte interactivo es que existe una posibilidad de "diálogo", y que además existe la posibilidad de crear redes o comunidades virtuales donde prime la conectividad sobre el contenido, según los intereses de cada usuario. De tal manera que se produce un modelo no jerárquico y horizontal (Baigorri y Cilleruelo, 2006, pp. 36-37).

\section{Limitaciones en la práctica de la apropiación audiovisual: el copyright}

Lessig (2000) comenta cómo las leyes de propiedad intelectual se han ido beneficiando de una particular retórica que equipara la "propiedad creativa" con los dueños de cualquier propiedad privada (p. 138). La producción creativa por tanto se convierte en mercancía y se crean leyes para su protección.

El copyright apoya a ciertas tendencias privatizadoras y desreguladoras, que reducen un buen número de "voces" (Canclini, 1995, p. 25) en las distintas capas sociales, y sobre todo en la popular.

En sentido estricto, la propiedad intelectual y derechos de autor son medidas proteccionistas de la integridad de las obras y protege al realizador de la misma, tanto al prestigio de llevar su nombre, como a la actividad económica derivada de la reproducción, distribución y exhibición.

Con la aparición de lo digital y de Internet, el copyright ya no sólo se limita a la distribución y a la copia, sino al consumo (Smiers, 2006, p. 97). La verdadera batalla librada en Internet, se centra en el control de las imágenes, más que en la diversidad cultural y en el potencial creativo del medio. Tal como apuntan Baigorri

ICONO14 | Año 2014 Volumen 12 N² 2 | ISSN: 1697-8293 | DOI: ri14.v12i2.719 
y Cilleruelo (2006, p. 142), los search engines, por ejemplo, son auténticos filtros conceptuales que ofrecen una visibilidad jerarquizada.

Una de las reflexiones más interesantes que nos aporta Smiers (2006, p. 70) es que el copyright más que establecer un equilibrio entre el beneficio económico y la integridad de la obra-autor, genera una desigualdad. La aplicación del copyright no se produce de forma igual en las creaciones de todas las partes del planeta y se elimina por tanto la diversidad. Pues, la mayoría de los productos culturales provenientes de las grandes industrias se realizan, en algunas zonas, lejos de la sociedad en la que viven. Por lo tanto, son percibidos para muchos como los únicos existentes. Estas medidas operan, en consecuencia, en contra de la creatividad (Smiers, 2006).

Lessig (2003) añade que el copyright es "no sólo un derecho exclusivo sobre tus escritos, sino un derecho exclusivo sobre tus escritos y una proporción muy grande de los escritos que inspire" (p. 160).

Hay una cuestión que merece especial interés para la práctica apropiacionista, $\mathrm{y}$ es que se permite citar a la obra siempre y cuando obedezca a una finalidad analítica o crítica, o la finalidad de su uso obedezca a fines educativos, o de investigación, con la condición de citar debidamente la fuente (Vilches, 2009, p. 67). La lectura sobre este punto puede resultar ambigua, sobre todo si se entiende la práctica de la apropiación audiovisual como una "cita" o como una obra derivada. Se construye una nueva obra con el material preexistente, que en muchos casos se manipula hasta hacer poco discernibles sus características visuales y sonoras, 0 se realiza una parodia -a veces explícita- de las obras apropiadas (Vilches, 2009).

En 1988, por ejemplo, Jeff Koons realizó su obra "Puppies" a partir de la apropiación de una imagen de una postal de Rogers. Supuso un pleito legal ya que se consideraba que no se hacía ningún comentario crítico. Este acontecimiento, como uno de tantos, demuestra cómo se han encontrado con problemas legales en el desarrollo de la obra apropiacionista (Martin Prada, 2001, p. 82).

En los últimos años, no obstante, han surgido nuevas formas de gestionar los 
derechos sobre la creación, y han surgido nuevos modelos de registrar las diferentes obras, donde además se puede observar una garantía y empuje para las mismas $Y$ esto se ha producido gracias al acceso masivo de creadores a nuevas formas de difusión de contenidos. El dominio público en la Red se fomenta con el desarrollo de organizaciones digitales que usan por ejemplo creative commons o copyleft ${ }^{6}$. Éste último, por ejemplo, posibilita el libre uso de las copias para su distribución y usos en obras derivadas, para que los mismos derechos se transfieran a éstas. Así como webs o bases de datos que contienen datos con imágenes, sonidos o vídeo de acceso y apropiación libre: (http://www.freesound.org/; http://straycinema. com;http://www.jamendo.com/es; etc.).

\section{Resultados. Entre la práctica artística y la táctica crítica}

En el nuevo panorama de la creación audiovisual contemporánea se puede comprobar que ciertas formas de expresión cultural, hasta la revolución tecnológica de los medios de reproducción en un primer momento, y la revolución digital e Internet por otro, han permanecido ligadas a una autorreferencialidad, que han tenido que trascender, para hablar sobre el entorno, releyendo y reconstruyendo una realidad social que permanecía al margen de los procesos culturales. Y se han diluido en otras prácticas alternativas, que han penetrado incluso en otros sectores fuera de la producción hegemónica, de tal manera que son practicadas por todo tipo de usuarios.

De esta manera se establece un tejido de micronarrativas que ofrecen resistencia a los sistemas de producción dominantes (París, s.f).

De la misma manera, la imagen artística se vuelve no corpórea y efímera, debido en parte a la evolución de las prácticas anti-institucionales, y por otro lado, a la inclusión de las tecnologías de producción de imagen digital en la creación artística. De esta manera, las imágenes artísticas se tornan, al mismo tiempo, accesibles y ubicuas.

Por otra parte hay que advertir que Internet, concebido como un espacio para la creación, difusión e información, se convierte en nuevo territorio que acoge 
diversas pertenencias identitarias que se han trasladado desde las identidades socialmente indefinidas que ofrecía la cultura posmoderna. De tal manera que este territorio ofrece una experiencia vital, que la cultura local, el nacionalismo o la religión no ofrece con tal contundencia como el espacio informativo y comunicativo digital (Vilches L., 2001, citado en De la Cuadra, 2007, p. 31).

Existen plataformas como youtube o vimeo, donde usuarios cuelgan todo tipo de vídeos, con diferentes finalidades. Éstas son muy populares y vitales para el desarrollo de esta práctica, ya que permiten la difusión de las obras apropiacionistas de forma libre y que las mismas sean comentadas y analizadas.

Hay autores que convienen en apuntar cómo la aparición de esta práctica nace como consecuencia de la multiplicación de la oferta del audiovisual (Bonet, 2002; Burriaud, 2007, Vilches, 2009). Como si fuera un resultado inevitable para poder interrogar la realidad, ya que, tal como advierte Bonet (2002): "el asunto de estos reciclajes desmontadores no es tanto la realidad como su simulacro; su representación y mediatización a través del derroche público de las imágenes y sus excedentes."(párr. 7).

Esta reflexión del autor posibilita que se establezcan dos grandes tipologías: una que trabaje sobre la crítica representacional y sobre la producción de significado; que al mismo tiempo moldea la conducta. $Y$ aquellas prácticas que hablan sobre la producción que pasa desapercibida, bien amateaur o la que es construida a través de diversas interacciones y colaboraciones de usuarios.

\subsection{Sobre la crítica representacional}

Una buena parte de las creaciones bajo la apropiación audiovisual están dedicadas a utilizar material cinematográfico o televisivo como medio para subvertir los estereotipos del mismo, su capacidad de crear modelos de vida y de conducta. Para ello hay que advertir que el principio creativo no consiste en yuxtaponer los elementos de forma inconexa y divergente, sino en una relación dialéctica en función de un desplazamiento del significado debido a su descontextualización (Paris, s.f). 
Los inicios del videoarte así lo confirmaron. De hecho la apropiación audiovisual surge en la década de los 70, donde movimientos como el "scratch video", con un discurso político, producen una serie de apropiaciones basadas en mecanismos propios de détournement, para desafiar la canónica vida especular propuesta de la TV y su influencia en los modos de vida de las generaciones más jóvenes (Vilches, 2009).

Dara Birnbaum es una de las primeras videoartistas que usan el principio creativo de la apropiación de imágenes audiovisuales de los mass-media para evidenciar la construcción de la identidad, especialmente de la mujer, en el medio televisivo. En su obra “Technology Transformation: Wonder Woman" (1978), se comprueba cómo realiza una deconstrucción de imágenes provenientes de la serie televisiva, donde a través de un efecto técnico, el personaje de una joven secretaría se convierte en una superheroína que lucha contra el crimen. La artista intenta por una parte, hacer una reflexión sobre los efectos visuales en el espectador, y por otra, presentar la figura de la protagonista como superheroína y como objeto de deseo. Para este fin la artista usa recursos como la repetición, en el momento en que se produce la transformación a través de un destello visual; a través de una transgresión del raccord; o la utilización de elementos simbólicos como el espejo.

Con este vídeo se pretende apelar a la parte subjetiva del espectador para introducirle en las sensaciones estéticas inducidas por el vídeo, al igual que sucediera en los videoclips, donde se rompe generalmente el sentido narrativo (Demos, 2010).

En él se disuelve la permanencia del tiempo, y a través de la repetición se intenta apelar a una reflexión sobre los estereotipos de género, que pasan inadvertidos en el contexto y fluir original de las imágenes.

El loop de una secuencia o una repetición en bucle, se muestra como recurso expresivo con diversos fines: la ridiculización, apelar a la memoria, etc.

Un ejemplo más reciente lo protagoniza "Hollywood Burn" (2011) una producción del colectivo Soda_Jerk y Sam Smith. Los autores del vídeo apuntan a que es una narración "épica" cuyo trasfondo consiste en atacar la absurda retórica del copyright y la piratería. Para ello construyen un disparatado argumento íntegramente con cientos de archivos visuales y sonoros sacados de material de películas 
y series de todo tipo de géneros y épocas, en el que una especie de "liga de la justicia" de piratas de vídeos, viajan en el tiempo y construyen un "video-clon" de Elvis Presley, para combatir "los mandamientos" sobre las políticas de derechos de autor de Moisés (http://www.sodajerk.com.au/index.php).
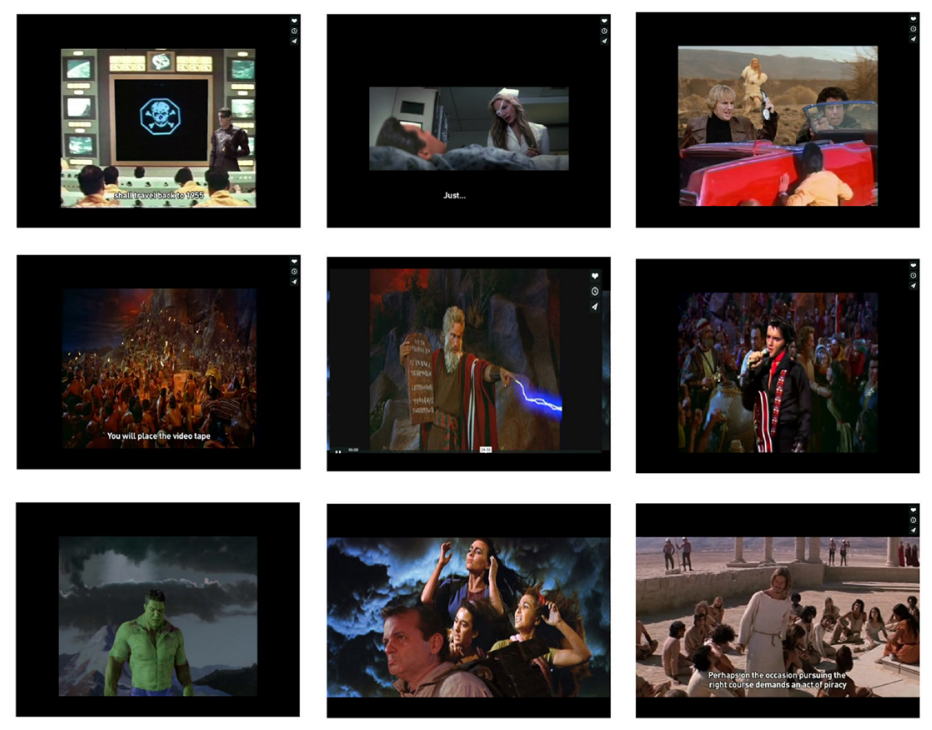

Figura 2: Frames de Hollywood Burn (2011). Fuente de elaboración propia a través de capturas de pantalla del vídeo (http://vimeo.com/45360616)

Para crear este hilo argumental los autores realizan un tedioso trabajo de archivo visual y sonoro, donde el extrañamiento se propicia a través de la yuxtaposición de elementos culturalmente contrapuestos como, por ejemplo, la solemnidad de las imágenes de películas bíblicas con la velocidad y dinamismo sonoro de algunas películas de ciencia-ficción y de música rock. Los autores al mismo tiempo usan todo tipo de recursos técnicos, no sólo con la experimentación del montaje, sobre todo del sonido, sino que además, se incrustan digitalmente motivos visuales en los diferentes frames, se cambian de color, eliminan elementos, etc. (Figura 2).

Otras producciones más modestas aunque de igual carga crítica, las podemos encontrar en blogs, youtube, vimeo, etc., por parte de usuarios anónimos, como el caso de la ofrecida por "Inappropiate Appropiation", en el que la autora habla 
de la inadecuada visión sobre los indios nativos americanos y que a través de la ficción cinematográfica se ha desvirtuado su identidad y su cultura. Para ello, la usuaria utiliza diferentes spots publicitarios, imágenes de Google y vídeos amateur de fiestas de disfraces de los indios nativos a los que contrapone de forma intermitente con imágenes de telediario donde se expone la situación real de las reservas, alejadas de la mítica cultura propuesta por los western (Figura 3).

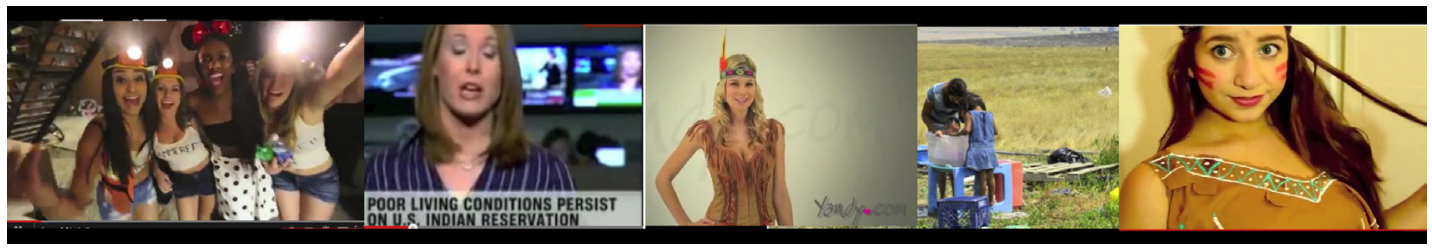

Figura 3: Frames de Inappropiate appropiation. Fuente de elaboración propia a través de captura de pantalla de la web youtube (https://www.youtube.com/watch?v=WHK1GXE8UAs)

\subsection{Cultura audiovisual intersticial}

Otra forma de entender esta práctica es a través de archivos no proporcionados por el mainstream, sino a través de aquellos documentos que o bien son desechados por los medios de comunicación porque son censurados, porque obedecen a una realidad diferente prefijada a los noticiarios y reportajes de éxito, documentales, etc.; o bien, porque simplemente no poseen las características necesarias para algún propósito comunicativo o estético (Bonet, 2002). En general, las propuestas más relevantes están interesadas en aquellos aspectos de la vida cotidiana que reflejan unas características y condiciones sociales determinadas, donde imperan las propias historias personales y privadas.

En este apartado también debería incluirse el vídeo amateur que registra una infinidad de eventos sociales y familiares, o reflexiones grabadas a cámara, entrevistas improvisadas, etc. Este material interesa mucho a artistas por su carácter de documento etnográfico o sociológico.

En esta línea estaría la videoinstalación de Christopher Baker "Hello World" (2008) de una exposición de la Saatchi Gallery de Londres. Se trata de un mosaico a través de una compilación de más de 5000 vídeos domésticos de youtube donde los

ICONO14 | Año 2014 Volumen 12 N² 2 | ISSN: 1697-8293 | DOI: ri14.v12i2.719 
internautas realizan un "vídeo-monólogo" a cámara de diferentes temas realizados en el ámbito de lo privado.

Esta instalación resulta confusa para el espectador por el enorme caos establecido por los audios conectados de forma sincrónica, y por la enormidad de la misma (Figura 4).
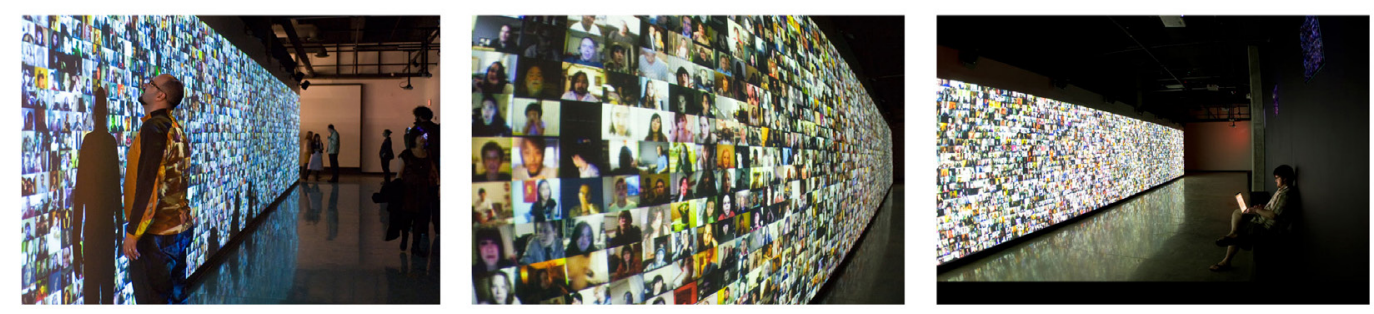

Figura 4: Hello World (2008). Fuente de elaboración propia a través de fotos de la web de Saatchi Gallery (http://www.saatchigallery.com/artists/christopher_baker.htm)

Este autor en esta especie de "paisaje audiovisual colectivo" trata de hacer ver el cambio drástico propiciado por el fenómeno del vídeo en Internet y la pluralidad promovida por una audiencia activa que trata de ser escuchada y de establecer un espacio de infinidad de opiniones, donde los usuarios puedan devolverle una respuesta, opinión o comentario (http://www.saatchigallery.com/artists/christopherbaker.htm).

Otro artista como Jasper Elings realiza también varias propuestas con material amateur. En su obra "Flashing in the mirrow" realiza una especie de animación a través de fotos realizadas frente a un espejo que los usuarios cuelgan en diferentes blogs o redes sociales. El flash que queda reflejado en la imagen especular describe a través de la obra un movimiento circular (Figura 5).

En esta obra se lanza una reflexión metafórica sobre una nueva configuración del "yo" a través de las imágenes que se publican en la Red, donde entra en juego la difícil relación entre lo público y lo privado.

Además de los vídeos domésticos existen otro tipo de recursos para dar un nuevo curso a estos documentos de lo "obsoleto" en los fondos recopilados por una 


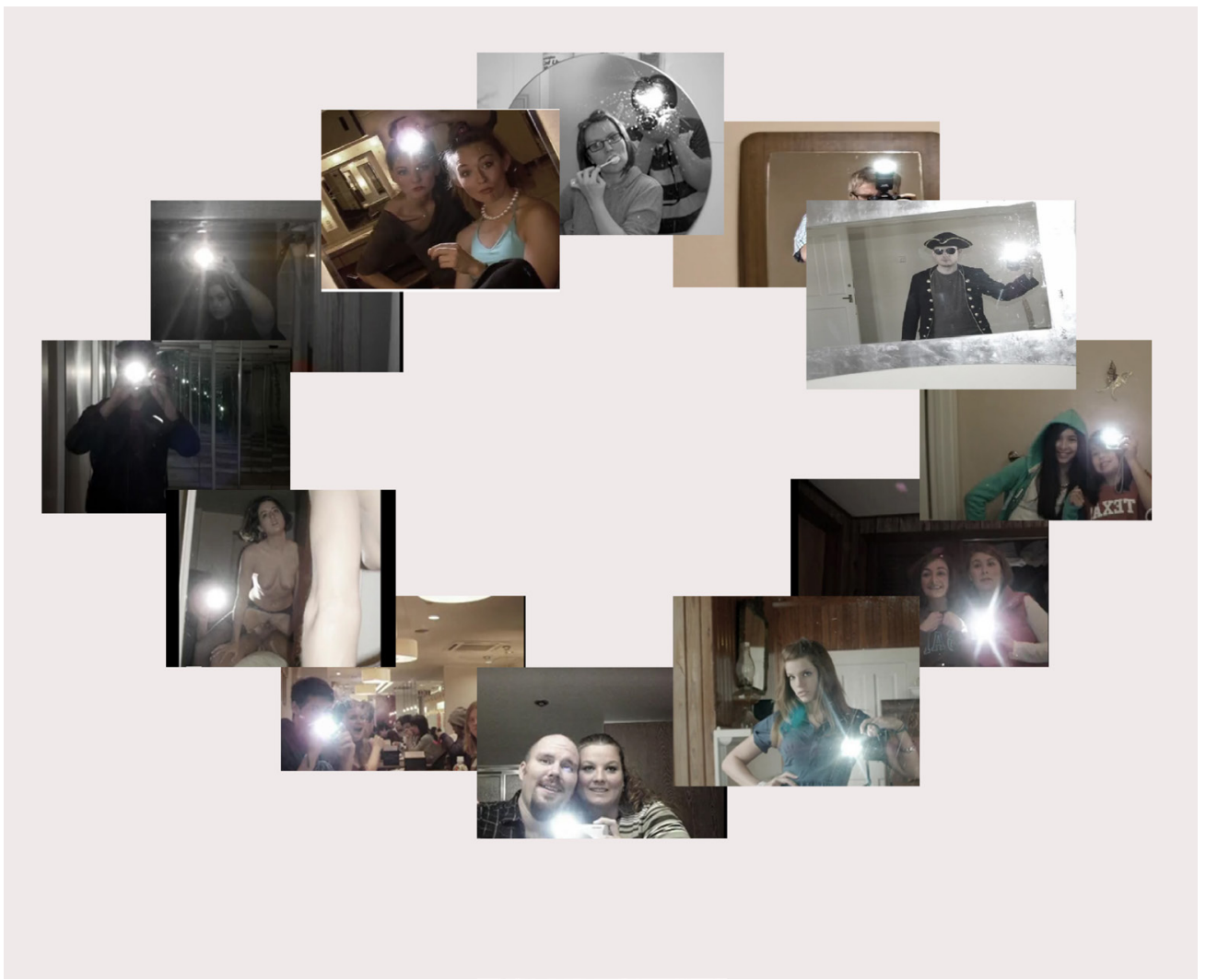

Figura 5: Frames de Flashing the mirrow. Fuente de elaboración propia a través de capturas de pantalla del vídeo en la web del artista (http://www.jasperelings.info/video/)

gran diversidad de archivos o "repositorios" audiovisuales (Bonet, 2002), como el de "archive.org", "straycinema.org", o blogs como "imovies.blogspot".

Cineastas y videoartistas los utilizan en busca de otros recursos alternativos, a los que se han sumado infinidad de usuarios anónimos.

Estos archivos digitales de dominio público se basan en la licencia creative commons o similares, donde el usuario puede descargarse los archivos y utilizarlos libremente. Estas webs son susceptibles de crecer a través de la inclusión de vídeos por parte de los usuarios, y están diseñadas para que se produzca un diálogo entre los mismos, en foros, blogs, etc. Además en algunos de ellos te dan algunas directrices de cómo realizar las obras. 
Los ejemplos que hay de acuerdo a estas premisas son miles. Esta especie de descartes conforma un material con potencial creativo unido a los miles de vídeos amateur que inundan la Red, que reflexionan sobre los intersticios de la producción y el consumo audiovisual.

\section{Discusión: Conclusiones y posibilidades}

La apropiación audiovisual como tal, no supone una práctica enteramente nueva, pero sí novedosa en cuanto que crea nuevas cotas de participación ciudadana y global a través de la Red, y posibilita la acción crítica sobre el nuevo paisaje mediático inundado de imágenes digitales disponibles gracias a la evolución de nuevos dispositivos de difusión, y también de reproducción.

Se podría enunciar que esta actividad es una respuesta a la "sociedad orwelliana", o táctica -en el sentido que Certeau lo comenta-, a las relaciones de poder inherentes en toda mediación cultural.

Tampoco es algo enteramente nuevo en la creación artística. Los artistas se nutren de los logros creativos y artísticos de sus predecesores. No se puede aislar una obra de la tradición. Además, mucha de la producción artística del Siglo XX es apropiacionista en sentido literal.

Lo novedoso en este caso sería que la apropiación audiovisual se desmarca de formas expresivas institucionalmente aceptadas como es el videoarte 0 incluso el cine, y al mismo tiempo, también se descontextualiza del espacio tradicional del arte del museo, para adentrarse y afianzarse como práctica en la Red. Debido a la disponibilidad de los documentos visivos del universo mediático, los repositorios y archivos, y el tipo de licencias alternativas como la comentada del copyleft, provocan que no sólo practiquen apropiación audiovisual aquellos que posean pretensiones artísticas, sino que sea una práctica activa popular entre los usuarios, y se creen redes de trabajo colaborativas donde prevalezca el hecho de la conectividad, y donde se inicien nuevas formas de sociabilidad. 
Los nuevos espacios de mediación cultural, por tanto, son también "escenarios para la creatividad" para que los propios usuarios sean copartícipes de una experiencia audiovisual colaborativa. El mainstream, en este caso, no es visto aquí como un impedimento o intrusismo para la creación.

Otra cuestión a resaltar es que se anula el trabajo manual en el proceso creativo, donde el artista/usuario selecciona y decide que porción de la realidad cultural utilizar. Este hecho confiere al propio "proceso" una importancia mayor sobre el "producto", y no sólo eso, sino que las propias características descritas de la apropiación sugieren que se produzca una reflexión sobre las imágenes, para dejar de asumirlas como un hecho incontrovertible, a través de interrogar, subvertir, y "deconstruir" las mismas, para elaborar un nuevo discurso.

Otra de las repercusiones que confiere esta práctica al mundo del arte es que la obra planteada como solución dada ya no es un referente. Por eso, el carácter imprevisible, no controlado, e incluso desconcertante de algunas obras apropiacionistas provoca que se formulen interrogantes, y que se creen continuos diálogos en torno al material apropiado, susceptible de ser manipulados y modificados por la enorme cantidad de usuarios.

En la pequeña selección de las obras, se puede comprobar que sustancialmente no existe una gran diferencia entre ambas y que lo único que las diferencia en muchos casos es el contexto de procedencia. La Red por tanto tiende a integrar estos espacios que formula esta práctica como actividad creativa y como actividad para ejercer ciudadanía. De esta selección, también se puede comentar que no importa la procedencia del material que es apropiado para el sesgo de la obra apropiacionista.

No obstante, esta práctica se encuentra en una situación difícil y comprometida en cuanto a que en muchas ocasiones estas prácticas son absorbidas por las instituciones o industrias culturales y de ocio, de tal manera que quedan neutralizados sus discursos.

Las leyes, y los dispositivos de control no siguen los nuevos paradigmas de creación que utilizan las nuevas tecnologías. Lo que bajo la óptica posmoderna se pue-

ICONO14 | Año 2014 Volumen 12 N² 2 | ISSN: 1697-8293 | DOI: ri14.v12i2.719 
de llamar pastiche, remix, cita, o incluso apropiación, hoy confiere la norma de la producción cultural asociada a nuevas tecnologías. Por lo que sigue permaneciendo una tensión dialéctica entre lo artístico y no artístico y lo "elevado" y lo "popular".

\section{Notas}

[1] Aquí se está utilizando para expresar esta idea el título de una de los ensayos de Paul Válery “ La conquête de l'ubiquité " (1928). En este ensayo el autor reflexiona sobre la transferencia de sensaciones en la recepción artística y sobre la reconstrucción en una nueva situación próxima a "la reproductibilidad técnica" propuesta por Benjamin.

[2] La cursiva es del autor. Este término alude a una teoría de T.W. Adorno por el cual se va perdiendo progresivamente las cualidades y valores tradicionales del arte.

[3] El autor indica que se aventura a usar el término "positiva" en sustitución de conservadora.

[4] "Bombardeados con impresiones fragmentadas [los ojos] ven demasiado y no registran nada. Así, la sobreestimulación y entumecimiento de forma simultánea es característico de la nueva organización sinestésica como anestésica. La inversión dialéctica, es la que la estética se convierte de un modo cognitivo al estar "en contacto" con la realidad a una manera de bloquearla, destruye el poder del organismo humano para responder políticamente" (trad. Autor).

[5] "Sin penetrar en la memoria, la experiencia se empobrece "(trad. Autor).

[6] Véase http://fundacioncopyleft.org/es/9/que-es-copyleft

\section{Referencias}

Alberich Pascual, J. y Roig Telo, A. (2012). Creación colectiva audiovisual y cultura colaborativa online. Proyectos y estrategias. Revista ICON014. Revista científica de Comunicación y Tecnologías emergentes, 8(1), 85-97. Recuperado en http://www.icono14.net (agosto, 2013).

Baigorri, L.y Cilleruelo L. (2006). Net.art (prácticas estéticas y políticas en la red). Barcelona: Editorial Brumaria.

Bal De, M. (2004). El esencialismo visual y el objeto de los estudios visuales. Estudios Visuales. $\mathrm{n}^{0} 2,11-51$.

Barthes, R. (2009). El susurro del lenguaje. Más allá de la palabra y la escritura. Barcelona: Paidós Ibérica.

Benjamin, W. (1990). Discursos interrumpidos I. Madrid: Taurus.

Bonet. E. (2002) Desmontaje Documental, en Culturas de Archivo, Recuperado de http://culturasdearchivo.org/modules.php?op=modload\&name=News\&file=pd 
$\mathrm{f} \& \mathrm{sid}=272$ (octubre, 2013).

Brea, J. L. (2002). La era postmedia: acción comunicativa, prácticas (post)artísticas y dispositivos neomediales. Salamanca: Consorcio Salamanca.

Buck-Morss, S. (2005). Estudios visuales e imaginación global. En J. L. Brea, (Ed.) Estudios visuales: la epistemología de la visualidad en la era de la globalización (pp.145-156). Tres Cantos (Madrid): Akal.

Buck-Morss, S. (1992). Aesthetics and Anaesthetics: Walter Benjamin's Art Works Essay Reconsidered. The MIT press. (62): 3-41. Recuperado en http://www.jstor.org/stable/778700 (febrero, 2014).

Burriaud, N. (2009). Postproducción. Buenos Aires, Ana Hidalgo editora.

Certeau, M ( 2000). La invención de lo cotidiano. Artes de hacer. México DF: Universidad Iberoamerica.

Colorado Nates, 0. (2012) Cindy Sherman, La niña de los disfraces. Recuperado en http://oscarenfotos.com/2012/08/18/cindy-sherman-la-nina-de-losdisfraces/ (enero, 2014).

Cuadra, A. (2007). La obra de arte en la época de su hiperreproductibilidad digital. Revista Digital ciencia Abierta. Universidad de Chile. Recuperado en http://cabierta. uchile. cl/revista/31/mantenedor/sub/articulos_1.pdf (noviembre, 2013).

Demos, T.J (2010). Dara Birnbaum, Technology/Transformation: Wonder Woman, Cambridge (London): MIT/Afterall Books.

Irvin, S. (2005). Appropriation and authorship in contemporary art. The British Journal of Aesthetics, 45(2), 123-137.

Jameson, F.(1991). El posmodernismo o la lógica cultural del capitalismo avanzado. Barcelona: Ed. Paidós.

Jiménez, J. (2010). Teoría del arte. Madrid: Ed. Tecnos.

Lessig, L. (2005). Cultura libre: Cómo los grandes grupos de comunicación utilizan la tecnología y la ley para clausurar la cultura y controlar la creatividad. Madrid: Traficantes de sueños.

Marchán Fiz, S (2005). Las Artes ante la Cultura Visual. Notas para una genealogía en la penumbra. En J. L. Brea, (Ed.) Estudios visuales: la epistemología de la visualidad en la era de la globalización (pp. 75-90). Tres Cantos (Madrid): Akal.

Martín Prada, J. M. (2001). La apropiación posmoderna: arte, práctica 
apropiacionista y teoría de la posmodernidad (Vol. 127). Madrid: Editorial Fundamentos.

Martín Prada, J. M. (2005). La enseñanza del arte en el campo interdisciplinar de los Estudios Visuales. En J. L. Brea, (Ed.) Estudios visuales: la epistemología de la visualidad en la era de la globalización (pp.131-144). Tres Cantos (Madrid): Akal.

Mitchell, W, J. T. (2005). “No existen medios visuales”. En J. L. Brea, (Ed.) Estudios visuales: la epistemología de la visualidad en la era de la globalización (pp.17-26) Tres Cantos (Madrid): Akal.

París, Ignacio (s.f) .Relectura y apropiación: cuando la creación está amenazada por la legalidad.Recuperado en http://www.ignacioparis.org/?page_id=28 (marzo, 2014)

Schumann, D. A. V. (2004). Nuevas tecnologías vs instituciones artísticas: El problema de la difusión y legitimación del arte realizado con nuevos medios. Del video-arte al net-art. En Arte y nuevas tecnologías: X Congreso de la Asociación Española de Semiótica (pp. 1024-1033). Universidad de La Rioja. Smiers, J. (2006). Un mundo sin copyright: artes y medios en la globalización. Barcelona: Gedisa.

Vilches, G (2009).Usos, estilos y formatos contemporáneos del audiovisual de apropiación en España. Recuperado en http://www.foundfootagehoy.com, (enero, 2014). 